\title{
Corticotropin-Releasing Factor and Acute Stress Prolongs Serotonergic Regulation of GABA Transmission in Prefrontal Cortical Pyramidal Neurons
}

\author{
Huibing Tan, Ping Zhong, and Zhen Yan \\ Department of Physiology and Biophysics, State University of New York at Buffalo, School of Medicine and Biomedical Sciences, Buffalo, New York 14214
}

\begin{abstract}
The stress-related neuropeptide corticotropin-releasing factor (CRF) and the serotonin system are both critically involved in the pathophysiology of mental disorders, including anxiety and depression. To understand the potential link between them, we investigated the impact of CRF on 5-HT functions in pyramidal neurons of the prefrontal cortex (PFC), a brain region that is crucial for the control of emotion and cognition. One prominent function of serotonin in PFC is to regulate GABAergic inhibitory transmission, as indicated by a 5 -HT-induced large, desensitizing ( $\sim 4 \mathrm{~min})$ enhancement of the amplitude and frequency of spontaneous IPSCs (sIPSCs). In PFC slices exposed to CRF treatment, the regulation of sIPSCs by 5 -HT was significantly prolonged $(8-10 \mathrm{~min})$, and this effect of CRF was blocked by treatment with the competitive CRF receptor antagonist $\alpha$-helical $\mathrm{CRF}_{9-41}$ and with the CRF-R1-specific antagonist astressin. Inhibiting phospholipase $\mathrm{C}$ or protein kinase $\mathrm{C}$ (PKC) abolished the prolongation by CRF of the effects of 5-HT on sIPSCs. In PFC slices prepared from animals previously exposed to acute stress (forced swim or elevated platform), the regulation of sIPSCs by 5-HT was significantly prolonged, mimicking the effect of CRF treatment. The stress-induced prolongation of the effects of 5-HT on sIPSCs was diminished by $\alpha$-helical $\mathrm{CRF}_{9-41}$ treatment, mimicked by direct activation of $\mathrm{PKC}$, and reversed by short-term treatment with drugs that have anxiolytic efficacy. These results show that in response to stressful stimuli, CRF alters the serotonergic regulation of GABA transmission through a mechanism that is dependent on PKC. The interaction between CRF and 5-HT may play an important role in psychiatric disorders, in which both are highly implicated.
\end{abstract}

Key words: prefrontal cortex; corticotropin-releasing factor; stress; IPSC; serotonin; PKC

\section{Introduction}

Corticotropin-releasing factor (CRF), a 41 aa neuropeptide, plays a key role in regulating physiological responses to stressful stimuli (Owens and Nemeroff, 1991). CRF is released from the hypothalamus and from extrahypothalamic neurons after stressor exposure (Tsigos and Chrousos, 2002) and displays a broad distribution in the brain (Sawchenko and Swanson, 1989). The peptide exerts a profound and complex impact on central neurons through its two receptors, CRF-R1 and CRF-R2 (Radulovic et al., 1999; Dautzenberg and Hauger, 2002). Mice deficient in CRF-R1 exhibit an impaired stress response and decreased anxiety-like behavior (Smith et al., 1998), whereas CRF-R2 mutant mice are supersensitive to stress and display increased anxiety-like behavior (Bale et al., 2000). CRF is implicated not only in the pathophysiology of affective and anxiety disorders but also in aversive states associated with drug withdrawal (Heinrichs et al., 1995; Sarnyai et al., 1995).

The serotonin system is also involved in mediating anxiety

Received Jan. 14, 2004; revised April 15, 2004; accepted April 19, 2004.

This work was supported by National Institutes of Health Grants MH63128 and AG-21923 and National Science Foundation Grant IBN-0117026 (Z.Y.). We thank Xiaoqing Chen for technical support.

Correspondence should be addressed to Dr. Zhen Yan, Department of Physiology and Biophysics, State University of New York at Buffalo, 124 Sherman Hall, Buffalo, NY 14214. E-mail: zhenyan@buffalo.edu.

DOI:10.1523/JNEUROSCI.0143-04.2004

Copyright $\odot 2004$ Society for Neuroscience $\quad$ 0270-6474/04/245000-09\$15.00/0 behaviors and stress responses (Deakin, 1988; Griebel, 1995; Shakesby et al., 2002). Mice lacking serotonin receptors show phenotypes ranging from increased impulsive aggression (Saudou et al., 1994) to elevated anxiety and an antidepressant-like response (Heisler et al., 1998; Gross et al., 2002). One of the main target structures of the serotonergic system is the prefrontal cortex (PFC), a brain region that is highly associated with the control of emotion and cognition (Miller, 1999). Specific changes in the PFC serotonin system found in patients with mental disorders (Stockmeier, 1997; Dean et al., 1999; Meyer et al., 1999) suggest that serotonin plays a crucial and unique role in PFC. One mechanism through which serotonin modulates PFC functions is via the regulation of $\mathrm{GABA}_{\mathrm{A}}$ receptor-mediated inhibitory synaptic transmission (Zhou and Hablitz, 1999; Feng et al., 2001; Cai et al., 2002; Yan, 2002). This regulation is potentially of clinical significance, because benzodiazepines (which reinforce transmission at $\mathrm{GABA}_{\mathrm{A}}$ receptors) and 5-HT-interacting agents are currently the principle drugs used in the management of anxiety disorders (Nutt et al., 1990; Taylor, 1990; Griebel, 1995; Gorman, 2003).

Given many of the common functional consequences of CRF and serotonin, we hypothesize that CRF may interact with the serotonin system, thereby aggravating behavioral responses to aversive stressors associated with anxiety and conditioned fear. Several lines of evidence have shown that CRF and stress interfere with serotonin neurotransmission by changing the firing rate of 
serotonergic neurons in dorsal raphe nuclei (DRN) and serotonin release (Adell et al., 1997; Maswood et al., 1998; Lowry et al., 2000). It is not known whether CRF modulates the synaptic functions of serotonin in limbic forebrain regions. In this study, we investigated the possibility that CRF and acute stress alter the 5-HT regulation of GABA transmission in PFC neurons. Because $\mathrm{GABA}_{\mathrm{A}}$ receptors are highly involved in anxiety and depression (Macdonald and Olsen, 1994; Lydiard, 2003), and GABAergic inhibition in PFC is a key element in the regulation of "working memory" (Constantinidis et al., 2002), the CRF-induced alteration of the effect of 5-HT on GABA transmission could provide a mechanism for exacerbated deficiencies in emotional and cognitive processes under stressful conditions.

\section{Materials and Methods}

Electrophysiological recordings in slices. Young adult rat slices containing PFC were prepared as described previously (Zhong et al., 2003). All experiments were performed with the approval of State University of New York at Buffalo Animal Care Committee. In brief, animals were anesthetized by inhaling 2-bromo-2-chloro-1,1,1-trifluoroethane ( $1 \mathrm{ml} / 100 \mathrm{gm}$; Sigma, St. Louis, MO) and decapitated; brains were quickly removed, iced, and then blocked for slicing. The blocked tissue was cut in 300-400 $\mu \mathrm{m}$ slices with a Vibratome while bathed in a low $\mathrm{Ca}^{2+}(100 \mu \mathrm{M})$, HEPES-buffered salt solution (in mM: $140 \mathrm{Na}$ isethionate, $2 \mathrm{KCl}, 4$ $\mathrm{MgCl}_{2}, 0.1 \mathrm{CaCl}_{2}, 23$ glucose, 15 HEPES, and 1 kynurenic acid, $\mathrm{pH} 7.4$; $300-305 \mathrm{mOsm} / \mathrm{l})$. Slices were then incubated for $1-6 \mathrm{hr}$ at room temperature $\left(20-22^{\circ} \mathrm{C}\right)$ in an $\mathrm{NaHCO}_{3}$-buffered saline bubbled with $95 \%$ $\mathrm{O}_{2}-5 \% \mathrm{CO}_{2}$ (in mM): $126 \mathrm{NaCl}, 2.5 \mathrm{KCl}, 2 \mathrm{CaCl}_{2}, 2 \mathrm{MgCl}_{2}, 26 \mathrm{NaHCO}_{3}$, $1.25 \mathrm{NaH}_{2} \mathrm{PO}_{4}, 10$ glucose, 1 pyruvic acid, 0.05 glutathione, $0.1 \mathrm{~N}^{G_{-}}$ nitro-L-arginine, and 1 kynurenic acid, $\mathrm{pH} 7.4 ; 300-305 \mathrm{mOsm} / \mathrm{l}$.

To evaluate the regulation of spontaneous IPSCs (sIPSCs) in PFC slices, the whole-cell patch technique was used for voltage-clamp recordings using patch electrodes (5-9 M $\Omega$ ) filled with the following internal solution (in mM): $100 \mathrm{CsCl}, 30 \mathrm{~N}$-methyl-D-glucamine, $10 \mathrm{HEPES}, 1$ $\mathrm{MgCl}_{2}, 4 \mathrm{NaCl}, 5 \mathrm{EGTA}, 0.8$ 2-(triethylamino)- $\mathrm{N}$-(2,6-dimethylphenyl)acetamide, 12 phosphocreatine, $2 \mathrm{MgATP}, 0.2 \mathrm{Na}_{3} \mathrm{GTP}$, and 0.1 leupeptin, pH $7.2-7.3 ; 265-270 \mathrm{mOsm} / \mathrm{l}$. The slice $(300 \mu \mathrm{m})$ was placed in a perfusion chamber attached to the fixed stage of an upright microscope (Olympus, Melville, NY) and submerged in continuously flowing oxygenated artificial CSF. For blocking glutamate transmission, the AMPAkainate receptor antagonist 6-cyano-7-nitroquinoxaline-2,3-dione (20 $\mu \mathrm{M})$ and the NMDA receptor (NMDAR) antagonist $\mathrm{D}(-)$-2-amino-5phosphonopetanoic acid $(20 \mu \mathrm{M})$ were added to the recording solution. Cells were visualized with a $40 \times$ water-immersion lens and illuminated with near infrared (IR) light, and the image was detected with an IRsensitive CCD camera. A Multiclamp 700A amplifier (Axon Instruments, Foster City, CA) was used for these recordings. Tight seals (2-10 G $\Omega$ ) from visualized pyramidal neurons were obtained by applying negative pressure. The membrane was disrupted with additional suction, and the whole-cell configuration was obtained. The access resistances ranged from 13 to $18 \mathrm{M} \Omega$ and were compensated $50-70 \%$. Cells were held at $-70 \mathrm{mV}$ for the recording of spontaneous IPSCs. Application of the $\mathrm{GABA}_{\mathrm{A}}$ receptor antagonist bicuculline $(10 \mu \mathrm{M})$ completely blocked the sIPSCs, indicating that these synaptic currents are mediated by $\mathrm{GABA}_{\mathrm{A}}$ receptors.

The Mini Analysis Program (Synaptosoft, Leonia, NJ) was used to analyze synaptic activity. Individual synaptic events with fast onset and exponential decay kinetics were captured with threshold detectors in Mini Analysis software. All quantitative measurements were taken 4-6 min after drug application. Neurons used for statistical analysis were required to have synaptic events with stable frequencies and amplitudes during both control and drug application. The detection parameters for analyzing synaptic events in each cell in the absence or presence of drugs were the same. Statistical comparisons of the frequency and amplitude of synaptic currents were made using the Kolmogorov-Smirnov test. Numerical values were expressed as mean $\pm \mathrm{SEM}$.

Ligands such as human/rat CRF, $\alpha$-helical $\mathrm{CRF}_{9-41}$, astressin (Tocris
Cookson, Ellisville, MO), and serotonin (Sigma), as well as the secondmessenger reagents calphostin C, Gö6850 (i.e., bisindolylmaleimide I), phorbol 12-myristate 13-acetate (PMA), U73122, and myristoylated PKI[14-22] (Calbiochem, La Jolla, CA) were made up as concentrated stocks in water and stored at $-20^{\circ} \mathrm{C}$. Stocks were thawed and diluted immediately before use.

Stress paradigm. Two stress protocols (forced-swim test and elevatedplatform test) that have been described previously (Xu et al., 1997; Price et al., 2002; Roche et al., 2003) were used in our studies. In the swim tests, rats were placed in a cylindrical glass tank $(24.5 \mathrm{~cm}$ high $\times 18.5 \mathrm{~cm}$ diameter) filled with water to a depth of $20 \mathrm{~cm}$. The $20 \mathrm{~cm}$ depth allowed the rats to reach the bottom with their tails only. Rats were forced to swim in warm water $\left(24-26^{\circ} \mathrm{C}\right)$ for $30 \mathrm{~min}$. In the elevated-platform tests, rats were placed on an elevated platform $(20 \times 20 \mathrm{~cm})$ for $30 \mathrm{~min}$ in a brightly lit room. The animal showed behavioral "freezing" (i.e., immobility) for up to $10 \mathrm{~min}$. Approximately $30 \mathrm{~min}$ after the stress procedures, rats were anesthetized and killed. Experimental groups were matched so that a stressed rat and a control rat were killed on the same day and tissue was processed in parallel. In some experiments, rats were injected intraperitoneally with saline, fluoxetine $(20 \mathrm{mg} / \mathrm{kg})$, fluvoxamine $(5 \mathrm{mg} / \mathrm{kg})$, or diazepam $(3 \mathrm{mg} / \mathrm{kg})$ before they were exposed to the forced-swim stress. One injection was given $12 \mathrm{hr}$ before the stress experiments, and a second shot was sometimes given $45 \mathrm{~min}$ before the stress experiments.

Western blot analysis. To detect activated PKC, a phospho-PKC (pan) antibody that recognizes $\mathrm{PKC} \alpha, \mathrm{PKC} \beta_{\mathrm{I}}, \mathrm{PKC} \beta_{\mathrm{II}}, \mathrm{PKC} \epsilon, \mathrm{PKC} \eta$, and $\mathrm{PKC} \delta$ isoforms only when phosphorylated at a $\mathrm{C}$-terminal residue homologous to Ser660 of PKC $\beta_{\text {II }}$ was used in the Western blot analysis $(\mathrm{Gu}$ et al., 2003). After incubation, slices were transferred to boiling 1\% SDS and homogenized immediately. Insoluble material was removed by centrifugation $(13,000 \times g$ for $10 \mathrm{~min})$, and the protein concentration of each sample was measured. Equal amounts of protein from slice homogenates were separated on $7.5 \%$ polyacrylamide gels and transferred to nitrocellulose membranes. The blots were blocked with 5\% nonfat dry milk for $1 \mathrm{hr}$ at room temperature. Then the blots were incubated with the pan antibody (1:2000; Cell Signaling Technology, Beverly, MA) for 1 $\mathrm{hr}$ at room temperature. After being rinsed, the blots were incubated with a horseradish peroxidase-conjugated anti-rabbit antibody (1:2000; Amersham Biosciences, Arlington Heights, IL) for $1 \mathrm{hr}$ at room temperature. After three washes, the blots were exposed to the enhanced chemiluminescence substrate. Then the blots were stripped for $1 \mathrm{hr}$ at $50^{\circ} \mathrm{C}$, saturated in 5\% nonfat dry milk, and incubated with a PKC antibody (1:2000; Santa Cruz Biotechnology, Santa Cruz, CA) recognizing the $\alpha, \beta$, and $\gamma$ isoforms. Quantitation was obtained from densitometric measurements of immunoreactive bands on autoradiograms.

\section{Results}

Serotonergic modulation of GABA transmission is prolonged by CRF pretreatment

To test the potential interactions between CRF and serotonin, we examined the impact of CRF on 5-HT regulation of GABAergic inhibitory transmission in PFC. Slices were treated with or without CRF (200 nM) for 1-3 hr, followed by measurement of the effect of 5-HT on sIPSCs in PFC pyramidal neurons. CRF alone did not exhibit any significant effect on sIPSC amplitudes $(2.8 \pm 2.0 \% ; n=28 ; p>0.01$; ANOVA) or frequencies $(5.8 \pm$ $5.1 \% ; n=28 ; p>0.01$; ANOVA). As shown in Figure $1 A-C$, bath application of 5-HT $(40 \mu \mathrm{M})$ caused a reversible increase in the amplitude and frequency of sIPSCs. The increase reached a peak and then started to decline within minutes during extended application of 5-HT. However, in CRF-treated slices, the 5-HTinduced increase in sIPSC desensitized much more slowly (Fig. $1 D-F)$. In a sample of CRF-treated PFC pyramidal neurons that we examined (Fig. $1 G$ ), the duration of the effect of 5 -HT on the sIPSC was $8.1 \pm 0.7 \mathrm{~min}(n=50)$, which was significantly $(p<$ 0.001 ; ANOVA) longer than that in control cells ( $4.0 \pm 0.5 \mathrm{~min}$; $n=49$ ). In contrast to the prolongation by CRF of the effect of 5-HT, CRF treatment did not significantly alter the enhancing 
effect of 5-HT on sIPSC amplitudes (Fig. $1 H$ ) (control, $113 \pm 14.3 \%, n=49$; CRFtreated, $127.6 \pm 15.6 \%, n=50 ; p>0.01$; ANOVA) or sIPSC frequencies (Fig. 1I) (control, $347.8 \pm 34.3 \%, n=46$; CRFtreated, $242.2 \pm 40.4 \%, n=46 ; p>0.01$; ANOVA).

At the cellular level, CRF activates two types of receptors: CRF-R1 and CRF-R2 (Dautzenberg and Hauger, 2002). To confirm the involvement of CRF receptors in this process, we preincubated PFC slices with the nonspecific CRF receptor antagonist $\alpha$-helical $\mathrm{CRF}_{9-41}$ (De Souza, 1987; Miyata et al., 1999). As shown in Figure $2 A-D$, the CRF-induced prolongation of the effect of 5-HT on sIPSC was blocked by $\alpha$-helical $\mathrm{CRF}_{9-41}(3 \mu \mathrm{M})$ treatment. To test which type of CRF receptor is potentially involved, we also preincubated PFC slices with the CRF-R1-specific antagonist astressin (Gulyas et al., 1995). As shown in Figure 2, $E$ and $F$, astressin $(1 \mu \mathrm{M})$ blocked the CRF-induced prolongation of the effects of 5-HT on sIPSCs. In a group of cells we examined (Fig. $2 G$ ), the duration of the effect of 5-HT was increased to $7.8 \pm 1.2$ $\min (n=18)$ by CRF but was reduced to $4.0 \pm 0.5 \min (n=13)$ in the presence of $\alpha$-helical $\mathrm{CRF}_{9-41}$ and to $4.1 \pm 0.7 \mathrm{~min}$ $(n=12)$ in the presence of astressin, both of which were similar to the effect of $5-\mathrm{HT}$ alone $(3.9 \pm 0.6 \mathrm{~min} ; n=17)$. The enhancement of sIPSC amplitudes (Fig. $2 \mathrm{H}$ ) or frequencies (Fig. $2 I$ ) by 5 -HT was not affected by the CRF receptor antagonists. These results suggest that CRF, by activating CRF-R1 receptors, facilitates the functions of serotonin receptors.

To examine whether the effect of CRF is specific for 5-HT, we also tested the effect of CRF on muscarinic regulation of sIPSC. Application of the muscarinic ACh receptor agonist carbachol (20 $\mu \mathrm{M}$ for $20 \mathrm{~min}$ ) enhanced sIPSC amplitude (127.2 $\pm 31.2 \%$; $n=7)$ and frequency $(354.7 \pm 51.2 \% ; n=7)$, but no obvious desensitization was found with the muscarinic effect (duration, $16.8 \pm 4.5 \mathrm{~min} ; n=7)$. CRF treatment did not alter the muscarinic regulation of GABA transmission (amplitude increase, $154.6 \pm 27.5 \%$; frequency increase, $390.7 \pm 47.5 \%$; duration, $15.6 \pm 2.8 \mathrm{~min} ; n=10$ ).

\section{CRF prolongs the effect of 5-HT on sIPSC through a phospholipase C/PKC-dependent mechanism}

We subsequently tried to identify the intracellular pathway through which CRF prolongs the effect of 5-HT on GABA transmission in PFC neurons. Because both CRF receptors are Gscoupled, the most notable signaling of CRF is the cAMP/PKA pathway (Dautzenberg and Hauger, 2002). However, when PKA was inhibited by bath application of myristoylated PKI[14-22] (1 $\mu \mathrm{M})$, the CRF-induced prolongation of the effect of 5-HT on sIPSC was still intact (Fig. 3A,B), suggesting the lack of involvement of PKA. In contrast, the phospholipase C (PLC)/PKC pathway has been shown to be involved in CRF potentiation of
B

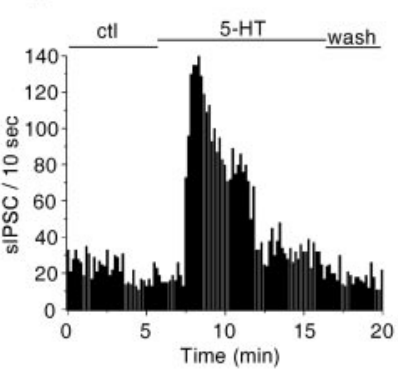

C

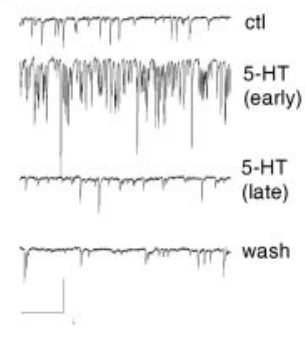

$\mathbf{F}$

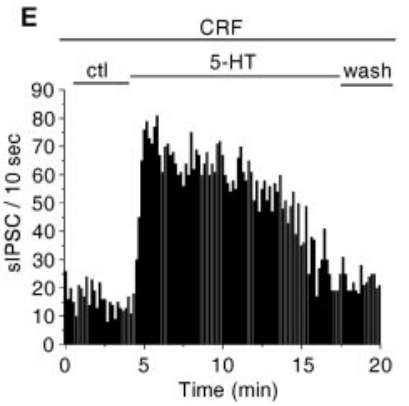

F $\quad$ CRF pretreated
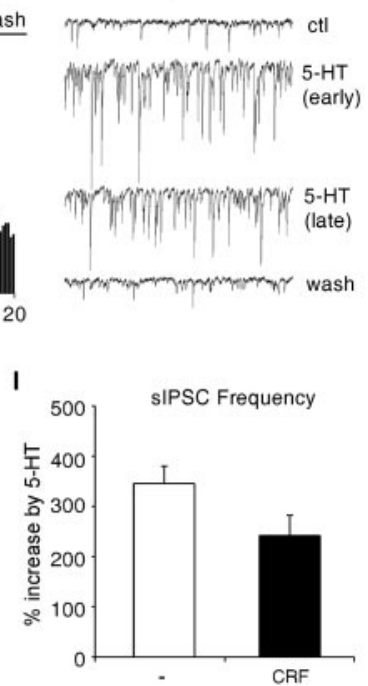

H

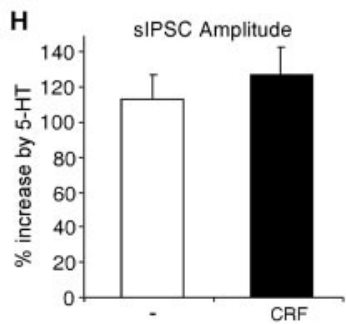

CRF

Figure 1. CRF treatment prolonged the enhancing effect of 5-HT on sIPSC in PFC pyramidal neurons. $A, B$, Plot of sIPSC ( $(A)$ and frequency $(B)$ against time and agonist (5-HT, $40 \mu \mathrm{m})$ application. C, Representative sIPSC traces recorded from Histograms (mean \pm SEM) showing the duration of the effects of 5 -HT on sIPSC in control neurons $(-; n=49)$ and CRF-treated neurons $(n=50) .{ }^{*} p<0.01$; ANOVA. $H, I$, Histograms (mean \pm SEM) showing the percentage increase in sIPSC amplitudes $(H)$ and frequencies $(/)$ by 5 - $\mathrm{HT}$ in control neurons and CRF-treated neurons.

NMDARs in dopamine neurons (Ungless et al., 2003) and CRF priming of long-term potentiation (LTP) in hippocampal neurons (Blank et al., 2002). Therefore, we tested whether inhibition of this pathway could interfere with the CRF-induced prolongation of the effect of 5-HT on sIPSC.

First, we bath-applied the PLC inhibitor U73122 (1 $\mu \mathrm{M})$ before and during CRF and 5-HT application. U73122 alone had no significant effect on the regulation of sIPSC by 5-HT (duration, $4.6 \pm 0.9 \mathrm{~min}$; amplitude increase, $83.5 \pm 13.1 \%$; frequency increase, $218.6 \pm 44.9 \% ; n=10$ ). However, in the presence of U73122, CRF failed to prolong the effect of 5-HT on sIPSC amplitudes and frequencies (Fig. 3C,D). Next, we tested the role of PKC by bath application of the cell-permeable and specific PKC inhibitor calphostin $\mathrm{C}(1 \mu \mathrm{M})$. Treatment with calphostin $\mathrm{C}$ did not significantly affect the regulation of sIPSC by serotonin (duration, $3.5 \pm 0.6 \mathrm{~min}$; amplitude increase, $78.6 \pm 8.5 \%$; frequency increase, $361.2 \pm 45.6 \% ; n=10)$. However, the CRFinduced prolongation of the effect of 5-HT on sIPSC was diminished by calphostin $\mathrm{C}$ treatment (representative examples shown in Fig. 3E,F). Another PKC inhibitor, Gö6850 (5 $\mu \mathrm{M})$, gave similar results (i.e., blocked the prolongation by CRF of the 

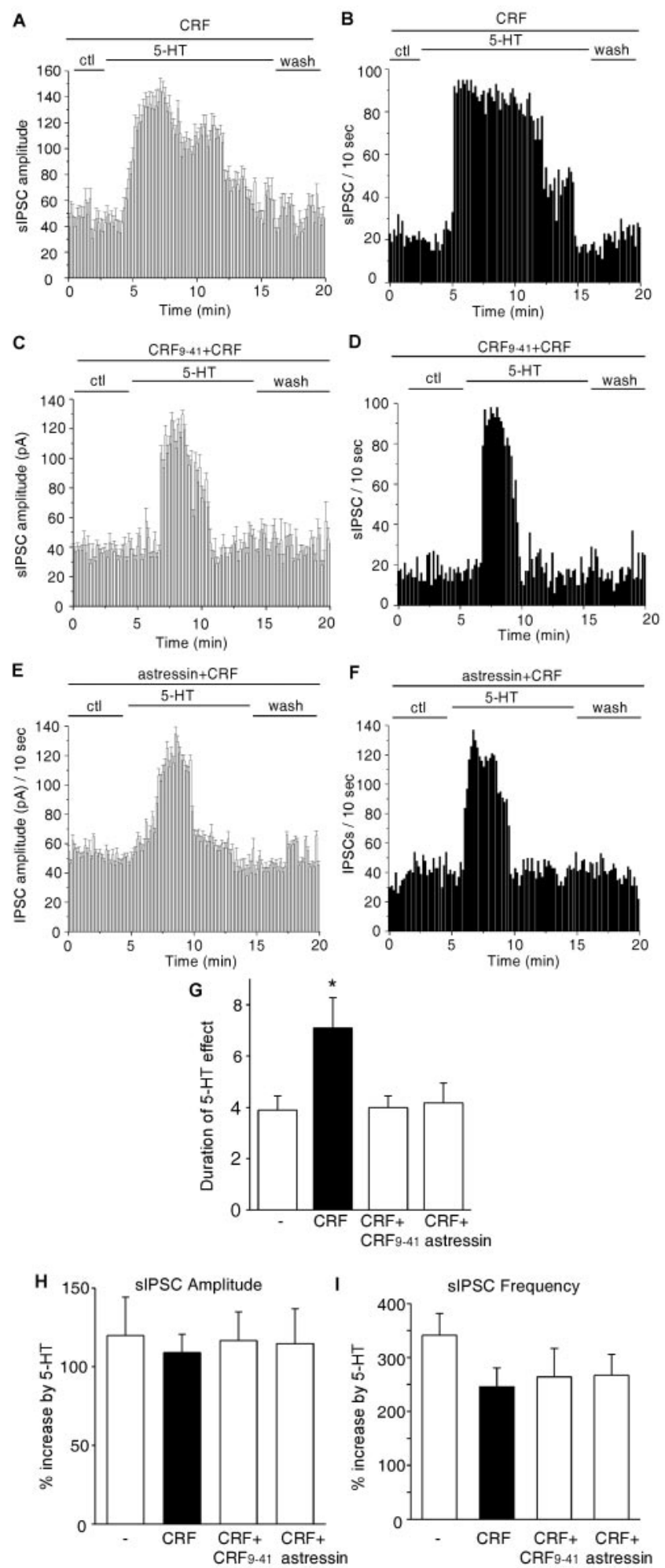

Figure 2. The CRF-induced prolongation of the effect of $5-\mathrm{HT}$ on SIPSC was blocked by CRF receptor antagonists. $A-F$, Plots of sIPSC amplitude $(A, C, E)$ and frequency $(B, D, F)$ against time and agonist (5-HT, $40 \mu \mathrm{M})$ application in a neuron exposed to CRF (200 nM) alone $(A, B)$, the nonspecific CRF receptor antagonist $\alpha$-helical $\mathrm{CRF}_{9-41}(3 \mu \mathrm{M})$ plus CRF (C, D), or the CRF-R1specific antagonist astressin $(1 \mu \mathrm{M})$ plus CRF $(E, F)$. ctl, Control conditions. G, Histograms (mean $\pm \mathrm{SEM}$ ) showing the duration of the effect of 5 -HT on $\operatorname{SIPSC}$ in control neurons $(-; n=$ 17), CRF-treated neurons ( $n=18)$, neurons treated with $\alpha$-helical CRF $_{9-41}$ plus CRF $(n=13)$, and neurons treated with astressin plus CRF $(n=12) .{ }^{*} p<0.01$; ANOVA. $H$, I, Histograms (mean \pm SEM) showing the percentage increase in sIPSC amplitudes $(H)$ and frequencies $(I)$ by 5 -HT under different treatments.
5-HT effect) (duration, $3.7 \pm 0.8 \mathrm{~min} ; n=13$ ), whereas Gö6850 alone did not significantly alter the effect of 5-HT on sIPSC (duration, $4.4 \pm 0.8 \mathrm{~min}$; amplitude increase, $105.8 \pm 24.3 \%$; frequency increase, $242.5 \pm 43.2 \% ; n=17$ ). As summarized in Figure $3 G$, in a group of cells that we examined, the duration of the effect of 5 -HT was increased to $8.8 \pm 1.2 \mathrm{~min}(n=14)$ by CRF in the presence of PKI[14-22] but was reduced to $3.1 \pm 0.5 \mathrm{~min}$ $(n=14)$ in the presence of $\mathrm{U} 73122$ and to $3.4 \pm 1.2 \mathrm{~min}(n=7)$ in the presence of calphostin $\mathrm{C}$, both of which were similar to the effect of 5 -HT alone $(3.9 \pm 0.6 \mathrm{~min} ; n=15)$. The 5 -HT enhancement of sIPSC amplitudes (Fig. $3 H$ ) or frequencies (Fig. 3I) was not affected by CRF coapplied with these inhibitors. These results suggest that CRF, by activating the PLC/PKC pathway, prolongs the serotonergic regulation of GABA transmission in PFC neurons.

We then examined whether CRF treatment can indeed increase PKC activity in rat PFC slices. Because the catalytic competence of many $\mathrm{PKC}$ isozymes depends on autophosphorylation at the $\mathrm{C}$ terminus on a conserved residue (Behn-Krappa and Newton, 1999), a phospho-specific pan PKC antibody that detects $\mathrm{PKC}$ isoforms only when phosphorylated at this residue was used to detect activated PKC (Gu et al., 2003). As shown in Figure $4 A$, application of CRF ( $200 \mathrm{~nm}, 1 \mathrm{hr}$ ) to cortical slices induced a marked increase in the activated PKC. The levels of total PKC were not changed by the treatment. Quantification data (Fig. 4B) exhibited a $3.5 \pm 0.8$-fold increase in PKC activity by CRF treatment $(n=4)$. These results suggest that CRF can elevate the kinase activity of PKC in PFC neurons.

\section{Acute stress prolongs serotonergic regulation of sIPSC by activating CRF/PKC signaling}

Because CRF plays an important role as a mediator of the stress response in the brain (Turnbull and Rivier, 1997; Eckart et al., 1999), we subsequently examined whether acute stress influences the effect of serotonin on GABAergic inhibitory transmission. The stress procedures we used entailed forcing the rat to swim in deep water for $30 \mathrm{~min}$ (Price et al., 2002; Roche et al., 2003) or placing the rat on the elevated platform for $30 \mathrm{~min}$ (Xu et al., 1997). As shown in Figure 5A-D, the 5-HT-induced increase in sIPSC amplitudes and frequencies was substantially prolonged in the PFC neuron from a swim-stress rat compared with the PFC neuron from a nonswim control rat. As summarized in Figure 5E, the duration of the effect of 5-HT on sIPSC was $9.3 \pm 1.2 \mathrm{~min}$ $(n=21)$ in the group of cells from animals exposed to the forcedswimming stress ( 12 animals) and $10.1 \pm 1.5 \mathrm{~min}(n=15)$ in the group of cells from animals exposed to the elevated-platform stress (eight animals), both of which were significantly longer than that in control cells $(3.9 \pm 0.8 \mathrm{~min} ; n=26)$ from nonstressed animals (20 animals). The enhancement by 5 -HT of sIPSC amplitudes (Fig. 5F) or frequencies (Fig. 5G) was not affected by these stressors.

Because acute behavioral stress produces an effect on the serotonergic regulation of GABA transmission that is similar to that seen with CRF treatment of PFC slices, we therefore tested whether the stress-induced change in 5-HT functions occurs through activation of CRF signaling. The CRF receptor antagonist $\alpha$-helical $\mathrm{CRF}_{9-41}$ was applied to pretreated PFC slices from stressed animals, followed by examination of the effect of 5-HT on sIPSC. As shown in Figure $6 A, \alpha$-helical $\mathrm{CRF}_{9-41}$ treatment (seven animals) significantly ( $p<0.01$; ANOVA) blocked the stress-induced prolongation of the effect of 5-HT (3.8 $\pm 0.5 \mathrm{~min}$; $n=20$ ). The enhancement by 5 -HT of sIPSC amplitudes (Fig. 

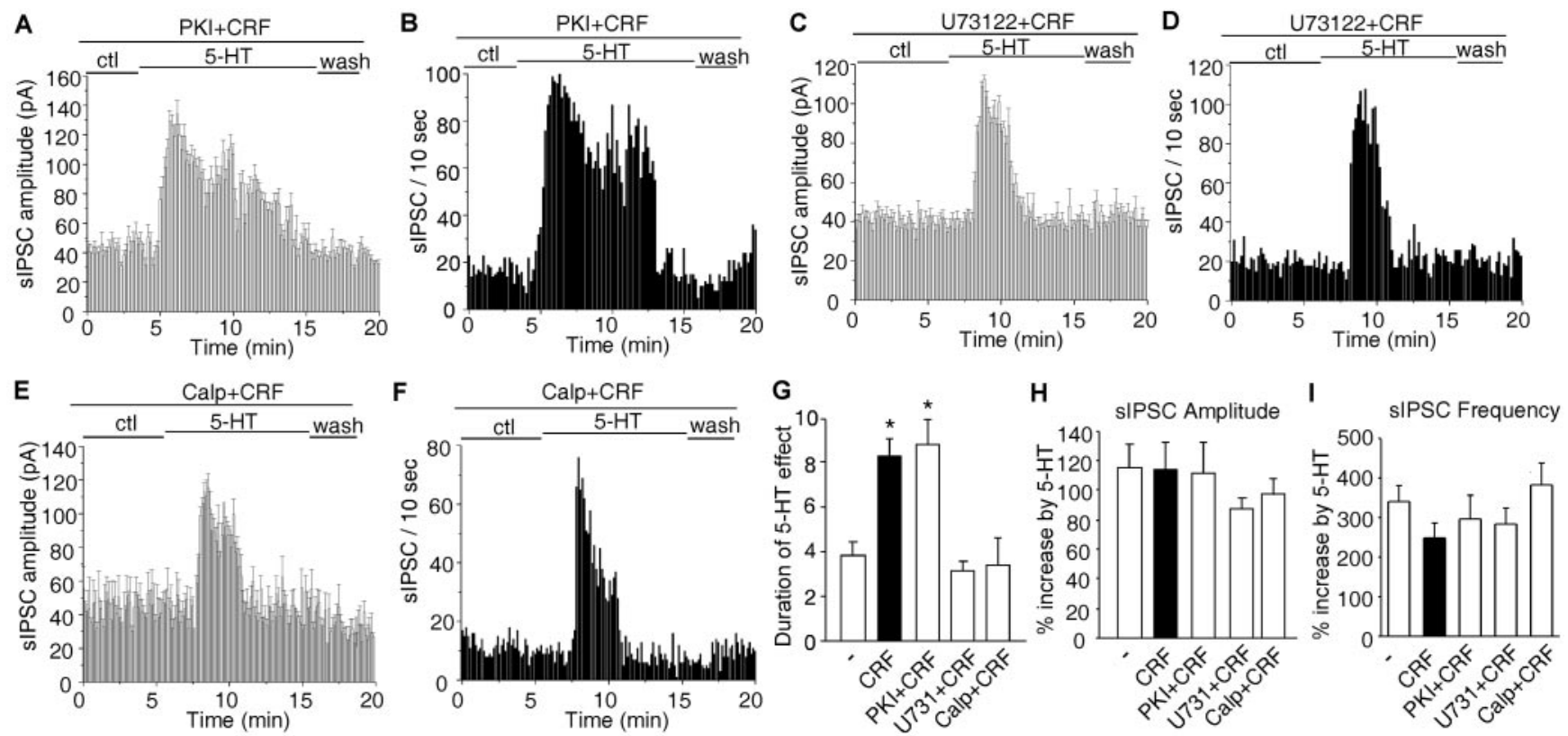

Figure 3. The CRF-induced prolongation of the effect of 5 -HT on sIPSC occurred through a mechanism that was dependent on the PLC/PKC pathway but not on PKA. $A-F$, Plot of sIPSC amplitude $(A, C, E)$ and frequency $(B, D, F)$ against time and agonist $(5-\mathrm{HT}, 40 \mu \mathrm{M})$ application in neurons exposed to CRF (200 nM) in the presence of the PKA inhibitor PKI $[14-22](1 \mu \mathrm{M})(A, B)$, the PLC inhibitor U73122 $(1 \mu \mathrm{M})(C, D)$, or the PKC inhibitor calphostin $C(C a l p ; 1 \mu \mathrm{M})(E, F)$. ctl, Control conditions. G, Histograms (mean \pm SEM) showing the duration of the effects of 5 -HT on sIPSCs in control neurons $(-; n=15)$, CRF-treated neurons $(n=16)$, and neurons treated with PKI plus CRF $(n=14)$, U73122 (U731) plus CRF $(n=14)$, or calphostin C plus CRF $(n=7) .{ }^{*} p<0.01$; ANOVA. H, I, Histograms (mean \pm SEM) showing the percentage increase in sIPSC amplitudes $(H)$ and frequencies $(I)$ by 5 -HT under different treatments.

A

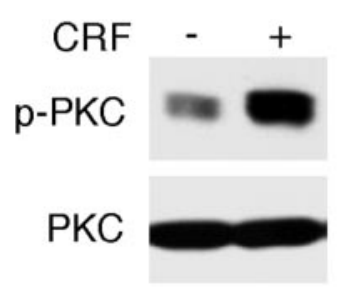

B

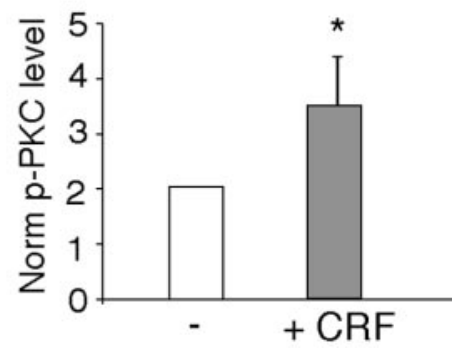

Figure 4. CRF treatment increased PKC activity in PFC slices. $A$, Immunoblots of phosphoPKC (p-PKC) and PKC. PFC slices were incubated in the absence or presence of CRF ( $200 \mathrm{~nm})$ for 1 hr. After treatment, slice lysates were blotted with an anti-phospho-PKC antibody. After stripping out signals, membranes were reblotted with an antibody recognizing the total PKC. $B$, Quantification of $p$-PKC in PFC slices treated without $(-)$ or with CRF. ${ }^{*} p<0.001$; ANOVA.

$6 B$ ) or frequencies (Fig. 6C) was essentially unaltered by $\alpha$-helical $\mathrm{CRF}_{9-41}$ in PFC slices from stressed animals.

Because CRF prolongs the serotonergic regulation of GABA transmission by activating the PLC/PKC pathway (Fig. 3), we further examined the effect of the PKC activator PMA $(0.5 \mu \mathrm{M})$ on the regulation of sIPSC by 5 -HT. As shown in Figure $6, D$ and $E$, PMA treatment prolonged the effect of 5-HT on sIPSC amplitudes and frequencies (duration, $9.4 \pm 1.5 \mathrm{~min} ; n=14$ ) (Fig. $6 \mathrm{~F}$ ), similar to the impact of CRF and acute stress. Together, these results suggest that stress, by activating the CRF/PKC pathway, prolongs the serotonergic regulation of GABA transmission in PFC neurons.

\section{Acute stress-induced alteration of the 5-HT regulation of} sIPSC is reversed by treatment with anti-anxiety drugs We then examined whether the stress-induced prolongation of the regulation by 5 -HT of GABA transmission in PFC neurons can be reversed by anxiolytic drugs. Selective serotonin reuptake inhibitors (SSRIs) such as fluoxetine are used to treat anxiety and panic disorders, in addition to treating depression (Zohar and Westenberg, 2000). In the animal model of learned helplessness, which is a biobehavioral model for stress-induced anxiety causing depression, SSRIs prevent helplessness (Petty et al., 1996). Therefore, we injected rats with fluoxetine before exposing them to the forced-swim stress procedure. As found commonly, changes in immobility in the forced-swim test (a predictive measure of antidepressant/anxiolytic efficacy) can be observed when fluoxetine is administered relatively acutely (within $24 \mathrm{hr}$ before the swim assessment).

Acute fluoxetine treatment did not significantly alter basal GABA transmission, as reflected by sIPSC mean amplitude (saline, $35.0 \pm 2.3 \mathrm{pA}, n=20$; fluoxetine, $39.2 \pm 4.1 \mathrm{pA}, n=5)$ and frequency (saline, $267 \pm 31.2$ events $/ \mathrm{min}, n=20$; fluoxetine, $283.8 \pm 51.6$ events $/ \mathrm{min}, n=5)$. Moreover, acute treatment with fluoxetine did not alter 5-HT regulation of GABA transmission, as shown by the 5-HT-induced increase in sIPSC amplitude (saline, $108.7 \pm 13.4 \%, n=20$; fluoxetine, $101.2 \pm 15.9 \%, n=5$ ) and frequency (saline, $283.5 \pm 38.6 \%, n=20$; fluoxetine, $265.5 \pm 40.6 \%, n=5$ ) and the duration of the 5-HT effect (saline, $4.2 \pm 0.5 \mathrm{~min}, n=20$; fluoxetine, $4.1 \pm 0.6 \mathrm{~min}, n=5$ ). However, in the neuron from a fluoxetine-injected rat, acute stress failed to prolong the serotonergic regulation of sIPSC (Fig. 7A, $B$ ).

Fluvoxamine, another potent SSRI, has demonstrated shortterm efficacy in the treatment of a number of anxiety disorders (Figgitt and McClellan, 2000). Therefore, we also tested the capability of fluvoxamine to reverse the acute stress-induced alteration of serotonin functions. Animals were injected intraperitoneally with fluvoxamine $(5 \mathrm{mg} / \mathrm{kg}) 12 \mathrm{hr}$ before exposure to the forced-swimming stress. As shown in Figure 7, $C$ and $D$, in the neuron from a fluvoxamine-injected rat, acute stress failed to prolong the serotonergic regulation of sIPSC.

To test whether other nonserotonergic anti-anxiety com- 
A

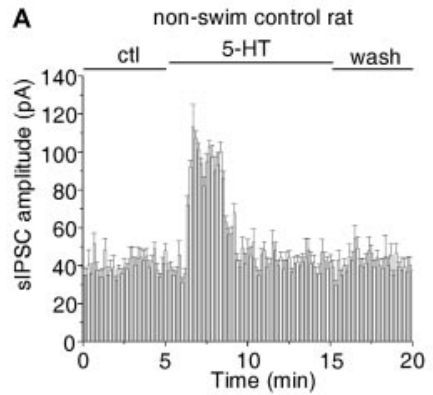

C swim-stress rat

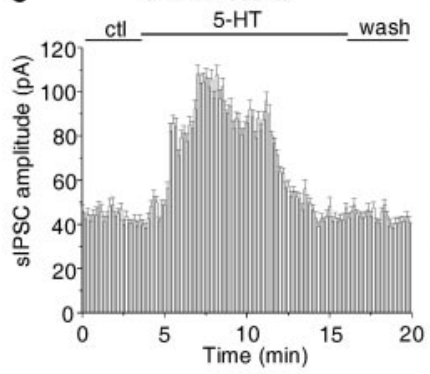

E

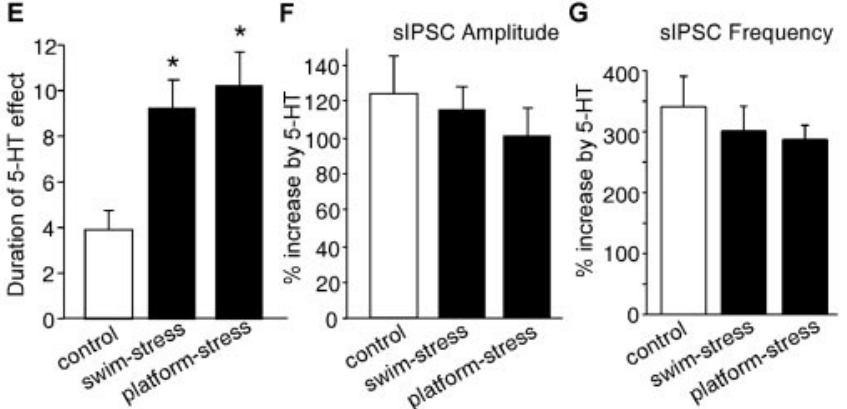

Figure 5. Acute stress prolonged the effect of 5-HT on sIPSC. $A-D$, Plot of sIPSC amplitude ( $A$, $C$ and frequency $(B, D)$ against time and agonist (5-HT, $40 \mu \mathrm{m})$ application in neurons from a nonswim control rat $(A, B)$ or a swim-stress rat $(C, D)$. ctl, Control conditions. $E$, Histograms (mean \pm SEM) showing the duration of the effects of 5-HT on sIPSCs in neurons from nonstressed control rats $(n=26)$, rats exposed to swim stress $(n=21)$, or rats exposed to elevated-platform stress $(n=15)$. ${ }^{*} p<0.01$; ANOVA. $F, G$, Histograms (mean \pm SEM) showing the percentage increase in sIPSC amplitudes $(F)$ and frequencies $(G)$ by 5 -HT under different conditions.

pounds are also able to restore serotonergic functions in stressed animals, we examined the effect of benzodiazepines, which have long been used to treat anxiety (Gorman, 2003). Animals were injected intraperitoneally with diazepam ( $3 \mathrm{mg} / \mathrm{kg}) 12 \mathrm{hr}$ before exposure to the forced-swimming stress. As shown in Figure 7, E and $F$, in the neuron from a diazepam-injected rat, acute stress lost the capability to prolong the serotonergic regulation of sIPSC.

Data from stressed animals treated with or without different anti-anxiety drugs are summarized in Figure $7 G$. In the group of cells from saline-injected rats (seven animals), the duration of the effect of 5 -HT was increased to $10.2 \pm 1.3 \mathrm{~min}(n=13)$ by acute stress, whereas in the group of cells from fluoxetine-injected rats (seven animals), the duration of the effect of 5 -HT was $3.5 \pm 0.4$ $\min (n=16)$ in response to acute stress, which was similar to the effect of 5-HT in neurons from nonstressed animals $(3.8 \pm 0.6$ $\min ; n=10)$. The enhancement of sIPSC amplitudes and frequencies by 5 -HT in these stressed animals was not significantly altered by fluoxetine (amplitude increase, $113.7 \pm 20.0 \%$; frequency increase, $223.4 \pm 39.1 \% ; n=16$ ). In the group of cells
A

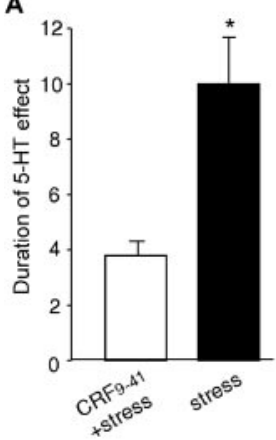

B
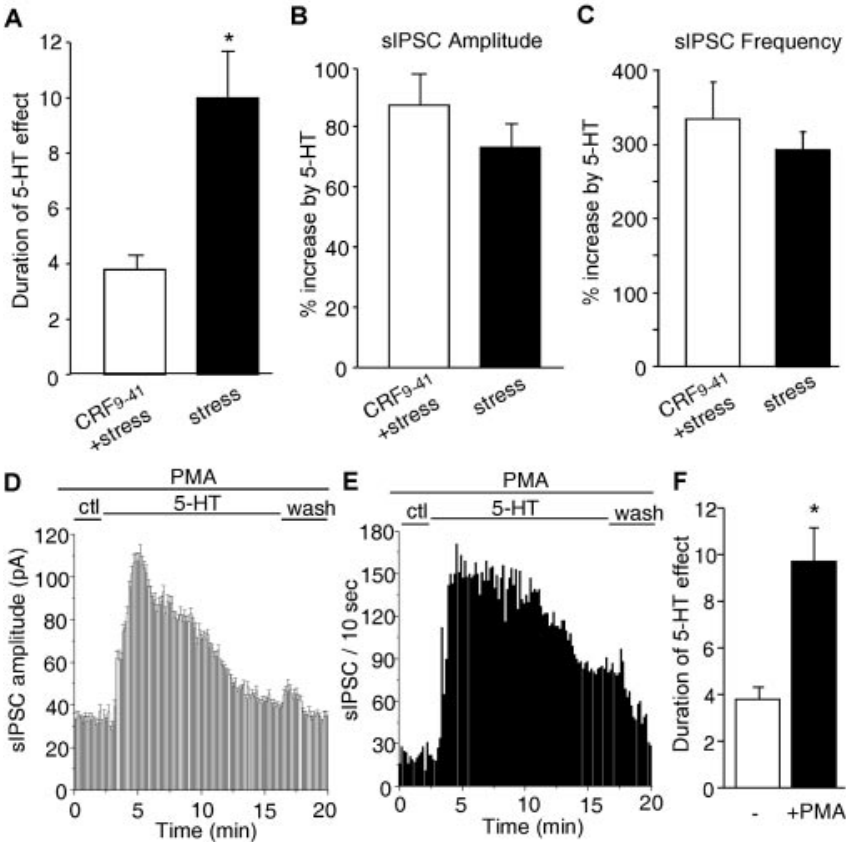

Figure 6. Stress-induced prolongation of the effect of 5-HT on sIPSC was blocked by a CRF receptor antagonist and mimicked by a PKC activator. $A$, Histograms (mean \pm SEM) showing the duration of the effect of 5 -HT on sIPSC in neurons from stressed animals treated with $(n=$ 20 ) or without $(n=24) \alpha$-helical CRF $_{9-41} \cdot{ }^{*} p<0.01$; ANOVA. B, C, Histograms (mean \pm SEM) showing the percentage increase in SIPSC amplitudes $(B)$ and frequencies $(C)$ by 5 -HT under different treatments. $D, E$, Plot of sIPSC amplitude $(D)$ and frequency $(E)$ against time and agonist (5-HT, $40 \mu \mathrm{m}$ ) application in a neuron exposed to the PKC activator PMA (0.5 $\mu \mathrm{M})$. Slices were pretreated with PMA for $1 \mathrm{hr}$, and PMA was present throughout the recordings. ctl, Control conditions. F, Histograms (mean \pm SEM) showing the duration of the effects of 5 -HT on sIPSCS in control neurons $(-; n=8)$ and PMA-treated neurons $(n=14)$. ${ }^{*} p<0.01$; ANOVA.

from fluvoxamine-injected rats (three animals) or diazepaminjected rats (four animals), the duration of the effect of 5-HT was $4.2 \pm 0.5 \min (n=5)$ or $3.8 \pm 0.9 \min (n=7)$, respectively, in response to acute stress, similar to the effect of 5-HT in neurons from nonstressed animals $(3.8 \pm 0.6 \mathrm{~min} ; n=10)$. The enhancement of sIPSC amplitudes and frequencies by 5 -HT in these stressed animals was not significantly altered by fluvoxamine (amplitude increase, $116.4 \pm 31.1 \%$; frequency increase, $246.7 \pm 44.1 \% ; n=5$ ) or diazepam (amplitude increase, $112.1 \pm$ $35.1 \%$; frequency increase, $265.2 \pm 77.5 \% ; n=7)$. These results suggest that short-term treatment with anti-anxiety drugs can prevent acute stress from prolonging the serotonergic regulation of GABA transmission.

\section{Discussion}

Stress has been recognized to strongly influence cognitive and emotional processes subserved by PFC, including working memory, attention, and inhibition of inappropriate responses (Arnsten, 1998). Elucidation of the functional role of key neuromodulators, such as serotonin and dopamine, is central to understanding why prefrontal cortical deficits are so prominent in many mental illnesses that are exacerbated by stress (Mazure, 1995). The involvement of dopamine $D_{1}$ receptors in stressinduced impairment of PFC function has been documented (Murphy et al., 1996; Zahrt et al., 1997), whereas the involvement of serotonin receptors is essentially unknown.

In addition to affecting structural plasticity, including dendritic atrophy and neurogenesis (McEwen, 1999), stress also dramatically affects synaptic plasticity at excitatory synapses (Saal et 
A swim-stress + fluoxetine B swim-stress + fluoxetine
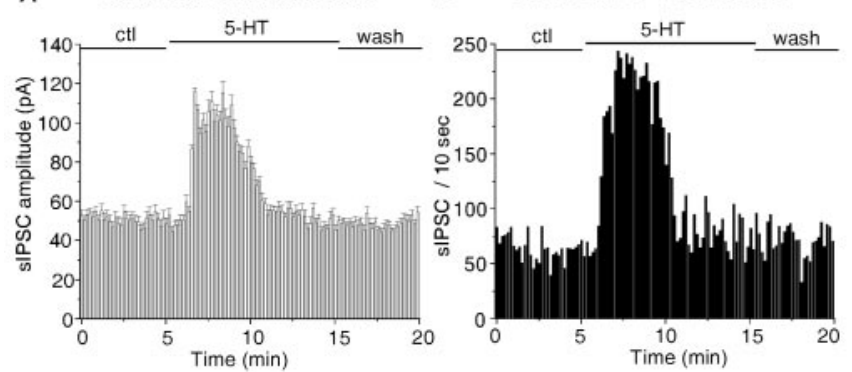

C swim-stress +fluvoxamine
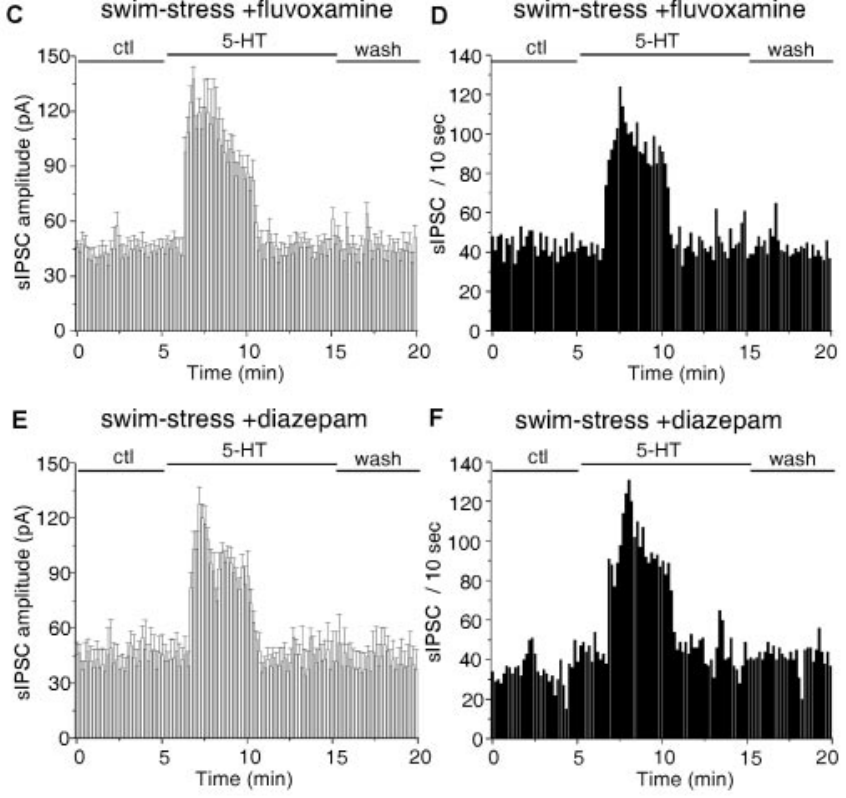

G

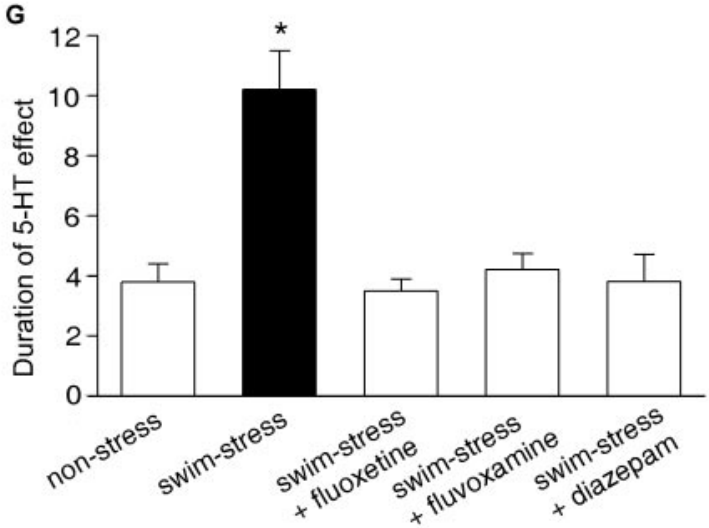

Figure 7. Short-term treatment with anti-anxiety drugs reversed the stress-induced prolongation of the 5 -HT effect on sIPSC. $A-F$, Plots of sIPSC amplitude $(A, C, E)$ and frequency $(B, D, F)$ against time and agonist $(5-\mathrm{HT}, 40 \mu \mathrm{m})$ application in a neuron from a swim-stress rat that has been injected intraperitoneally with fluoxetine $(20 \mathrm{mg} / \mathrm{kg} ; A, B)$, fluvoxamine $(5 \mathrm{mg} / \mathrm{kg} ; C, D)$, or diazepam ( $3 \mathrm{mg} / \mathrm{kg} ; E, F)$. ctl, Control conditions. G, Histograms (mean \pm SEM) showing the duration of effects of 5-HT on sIPSC in neurons from nonstressed control rats $(n=10)$, salineinjected rats exposed to swim stress $(n=13)$, fluoxetine-injected rats exposed to swim stress ( $n=16)$, fluvoxamine-injected rats exposed to swim stress $(n=5)$, or diazepam-injected rats exposed to swim stress $(n=7) .{ }^{*} p<0.01$; ANOVA.

al., 2003), a putative learning and memory mechanism. Acute stress blocks LTP induced by high-frequency stimulation (Shors et al., 1989; Xu et al., 1997; Maroun and Richter-Levin, 2003) and facilitates long-term depression induced by low-frequency stimulation (Kim et al., 1996; Xu et al., 1997). The effects of stress on synaptic plasticity can be overcome by lowering endogenous 5-HT levels (Shakesby et al., 2002), suggesting the involvement of serotonergic mechanisms in mediating stress responses. In agreement with this, many stressors produce a large accumulation of extracellular 5-HT within the DRN and forebrain regions, including PFC (Yoshioka et al., 1995; Adell et al., 1997; Maswood et al., 1998). This is probably attributable to the CRF-induced increase in the firing rates of 5-HT neurons in the caudal DRN and activation of mesolimbocortical serotonergic pathways during uncontrollable stress (Lowry et al., 2000). To understand the interactions between the stress-related neuropeptide CRF and the serotonin system, most studies have focused on the influence of $\mathrm{CRF}$ and stress on serotonin release and serotonergic neuron excitability (Adell et al., 1997; Maswood et al., 1998; Lowry et al., 2000; Price and Lucki, 2001). Little is known about the impact of CRF and stress on the function of serotonin in its target areas.

The findings of the present study are the first to show that acute stress alters the serotonergic regulation of GABA transmission (assayed by exogenous application of 5-HT) in PFC pyramidal neurons. This stress-induced alteration of the effect of 5-HT occurs through a mechanism that is dependent on CRF, which is demonstrated by two lines of evidence. First, CRF mimics the effects of acute stress on 5-HT regulation of GABA transmission. Second, the stress-induced alteration of the 5-HT regulation of GABA transmission is prevented by a CRF receptor antagonist. These results suggest that stress and CRF can affect not only 5-HT release but also the actions of 5-HT on its target neurons.

Serotonin, by activating different 5 -HT receptors, has a powerful and complex impact on GABAergic synaptic transmission in PFC neurons (Zhou and Hablitz, 1999; Feng et al., 2001; Cai et al., 2002; Yan, 2002). A prominent effect of 5-HT is the large increase in the amplitude and frequency of spontaneous IPSC (Zhou and Hablitz, 1999). One interesting feature of the 5-HT regulation of SIPSC is that the effect of 5-HT declines within 3-4 $\mathrm{min}$ in the continued presence of the agonist. However, in PFC slices pretreated with CRF or from stressed animals, the regulation of sIPSC by 5 -HT lasts much longer ( $8-10 \mathrm{~min})$. Therefore, after stressor exposure, more 5-HT will be released and 5-HT signaling will be prolonged, which could synergistically lead to potentiated and sustained regulation of GABAergic inhibition by 5-HT. Given the key role of PFC/GABAergic inhibition in shaping the temporal flow of information and thus the regulation of working memory (Constantinidis et al., 2002), the altered regulation of GABA transmission by serotonin in response to stressful stimuli could lead to disturbed PFC functions. In support of this possibility, the stress-induced alteration of the effect of 5-HT on GABA transmission is reversed by fluoxetine, fluvoxamine, and diazepam, all of which have behavioral anxiolytic effects against stress-induced anxiety (Petty et al., 1996; Figgitt and McClellan, 2000; Zohar and Westenberg, 2000; Gorman, 2003). In cells from acute SSRI-treated animals, the exogenously applied 5-HT induced a transient enhancing effect on spontaneous GABA transmission, similar to what was found in control cells. This suggests that the functions of 5-HT receptors are not significantly altered by acute SSRI treatment. Although SSRIs can block reuptake of 5 -HT, they are not able to change the action of an exogenously applied high concentration of 5-HT $(40 \mu \mathrm{M})$.

The cellular mechanism that may underlie the prolongation by CRF of the 5-HT effect on GABA transmission in PFC neurons was also investigated. It has been shown that CRF receptors couple to multiple G-proteins to activate diverse intracellular signaling pathways in mouse hippocampus (Blank et al., 2003). We found that the PLC/PKC pathway is involved in the 
CRF-induced alteration of the effect of 5-HT on sIPSC in rat PFC neurons, similar to the signaling involved in CRF potentiation of NMDARs in dopamine neurons (Ungless et al., 2003) and CRF facilitation of LTP in hippocampal neurons (Blank et al., 2002). How CRF/PKC prolongs the regulation of sIPSC by $5-\mathrm{HT}$ is unclear. Two mechanisms could account for the effect of 5-HT on GABA transmission. First, serotonin elevates the excitability of GABAergic interneurons, therefore leading to the increased GABA release. Second, 5-HT enhances the probability of action potential-dependent GABA release from axon terminals, thereby leading to an increase in the contribution of large-size (multiquantal) sIPSCs to the overall population of synaptic events. Because the desensitizing effect of 5-HT on sIPSCs is not affected by PKC inhibitors, it is therefore unlikely to be mediated by a PKCmediated phosphorylation, desensitization, or internalization of 5-HT receptors (Raymond, 1991; Bhattacharyya et al., 2002). For the prolongation by CRF of the 5-HT effect on sIPSC, we speculate that released CRF in response to stressful stimuli potently activates PKC, and PKC phosphorylation of an unidentified regulatory protein causes a prolonged serotonin excitation of GABAergic interneurons or serotonin increase of GABA release at presynaptic terminals.

Together, the central finding of this study is that CRF and acute stress can alter the functions of 5-HT in PFC pyramidal neurons (i.e., prolong the enhancement by $5-\mathrm{HT}$ of spontaneous GABA transmission through a mechanism involving PKC). This finding provides a possible mechanism for the stress-induced exacerbation of psychiatric disorders that are associated with aberrant actions of serotonin.

\section{References}

Adell A, Casanovas JM, Artigas F (1997) Comparative study in the rat of the actions of different types of stress on the release of 5-HT in raphe nuclei and forebrain areas. Neuropharmacology 36:735-741.

Arnsten AF (1998) The biology of being frazzled. Science 280:1711-1712.

Bale TL, Contarino A, Smith GW, Chan R, Gold LH, Sawchenko PE, Koob GF, Vale WW, Lee KF (2000) Mice deficient for corticotropin-releasing hormone receptor-2 display anxiety-like behaviour and are hypersensitive to stress. Nat Genet 24:410-414.

Behn-Krappa A, Newton AC (1999) The hydrophobic phosphorylation motif of conventional protein kinase $\mathrm{C}$ is regulated by autophosphorylation. Curr Biol 9:728-737.

Bhattacharyya S, Puri S, Miledi R, Panicker MM (2002) Internalization and recycling of 5-HT2A receptors activated by serotonin and protein kinase C-mediated mechanisms. Proc Natl Acad Sci USA 99:14470-14475.

Blank T, Nijholt I, Eckart K, Spiess J (2002) Priming of long-term potentiation in mouse hippocampus by corticotropin-releasing factor and acute stress: implications for hippocampus-dependent learning. J Neurosci 22:3788-3794.

Blank T, Nijholt I, Grammatopoulos DK, Randeva HS, Hillhouse EW, Spiess J (2003) Corticotropin-releasing factor receptors couple to multiple G-proteins to activate diverse intracellular signaling pathways in mouse hippocampus: role in neuronal excitability and associative learning. J Neurosci 23:700-707.

Cai X, Flores-Hernandez J, Feng J, Yan Z (2002) Activity-dependent bidirectional regulation of $\operatorname{GABA}(\mathrm{A})$ receptor channels by serotonin $5-\mathrm{HT}(4)$ receptors in pyramidal neurons of the prefrontal cortex. J Physiol (Lond) 540:743-759.

Constantinidis C, Williams GV, Goldman-Rakic PS (2002) A role for inhibition in shaping the temporal flow of information in prefrontal cortex. Nat Neurosci 5:175-180.

Dautzenberg FM, Hauger RL (2002) The CRF peptide family and their receptors: yet more partners discovered. Trends Pharmacol 23:71-77.

Deakin JF (1988) 5HT2 receptors, depression and anxiety. Pharmacol Biochem Behav 29:819-820.

Dean B, Hussain T, Hayes W, Scarr E, Kitsoulis S, Hill C, Opeskin K, Copolov DL (1999) Changes in serotonin2A and GABA(A) receptors in schizo- phrenia: studies on the human dorsolateral prefrontal cortex. J Neurochem 72:1593-1599.

De Souza EB (1987) Corticotropin-releasing factor receptors in the rat central nervous system: characterization and regional distribution. J Neurosci 7:88-100.

Eckart K, Radulovic J, Radulovic M, Jahn O, Blank T, Stiedl O, Spiess J (1999) Actions of CRF and its analogs. Curr Med Chem 6:1035-1053.

Feng J, Cai X, Zhao J, Yan Z (2001) Serotonin receptors modulate GABA receptor channels through activation of anchored protein kinase $\mathrm{C}$ in prefrontal cortical neurons. J Neurosci 21:6502-6511.

Figgitt DP, McClellan KJ (2000) Fluvoxamine. An updated review of its use in the management of adults with anxiety disorders. Drugs 60:925-954.

Gorman JM (2003) Treating generalized anxiety disorder. J Clin Psychiatry 64 [Suppl 2]:24-29.

Griebel G (1995) 5-Hydroxytryptamine-interacting drugs in animal models of anxiety disorders: more than 30 years of research. Pharmacol Ther 65:319-395.

Gross C, Zhuang X, Stark K, Ramboz S, Oosting R, Kirby L, Santarelli L, Beck S, Hen R (2002) Serotonin1A receptor acts during development to establish normal anxiety-like behaviour in the adult. Nature 416:396-400.

Gu Z, Zhong P, Yan Z (2003) Activation of muscarinic receptors inhibits beta-amyloid peptide-induced signaling in cortical slices. J Biol Chem 278:17546-17556.

Gulyas J, Rivier C, Perrin M, Koerber SC, Sutton S, Corrigan A, Lahrichi SL, Craig AG, Vale W, Rivier J (1995) Potent, structurally constrained agonists and competitive antagonists of corticotropin-releasing factor. Proc Natl Acad Sci USA 92:10575-10579.

Heinrichs SC, Menzaghi F, Schulteis G, Koob GF, Stinus L (1995) Suppression of corticotropin-releasing factor in the amygdala attenuates aversive consequences of morphine withdrawal. Behav Pharmacol 6:74-80.

Heisler LK, Chu HM, Brennan TJ, Danao JA, Bajwa P, Parsons LH, Tecott LH (1998) Elevated anxiety and antidepressant-like responses in serotonin 5-HT1A receptor mutant mice. Proc Natl Acad Sci USA 95:15049-15054.

Kim JJ, Foy MR, Thompson RF (1996) Behavioral stress modifies hippocampal plasticity through $N$-methyl-D-aspartate receptor activation. Proc Natl Acad Sci USA 93:4750-4753.

Lowry CA, Rodda JE, Lightman SL, Ingram CD (2000) Corticotropinreleasing factor increases in vitro firing rates of serotonergic neurons in the rat dorsal raphe nucleus: evidence for activation of a topographically organized mesolimbocortical serotonergic system. J Neurosci 20:7728-7736.

Lydiard RB (2003) The role of GABA in anxiety disorders. J Clin Psychiatry 64 [Suppl 3]:21-27.

Macdonald RL, Olsen RW (1994) GABAA receptor channels. Annu Rev Neurosci 17:569-602.

Maroun M, Richter-Levin G (2003) Exposure to acute stress blocks the induction of long-term potentiation of the amygdala-prefrontal cortex pathway in vivo. J Neurosci 23:4406-4409.

Maswood S, Barter JE, Watkins LR, Maier SF (1998) Exposure to inescapable but not escapable shock increases extracellular levels of 5-HT in the dorsal raphe nucleus of the rat. Brain Res 783:115-120.

Mazure CM (1995) Does stress cause psychiatric illness? Washington, DC: American Psychiatric.

McEwen BS (1999) Stress and hippocampal plasticity. Annu Rev Neurosci 22:105-122.

Meyer JH, Kapur S, Houle S, DaSilva J, Owczarek B, Brown GM, Wilson AA, Kennedy SH (1999) Prefrontal cortex 5-HT2 receptors in depression: an $\left[{ }^{18} \mathrm{~F}\right]$ setoperone PET imaging study. Am J Psychiatry 156:1029-1034.

Miller EK (1999) The prefrontal cortex: complex neural properties for complex behavior. Neuron 22:15-17.

Miyata M, Okada D, Hashimoto K, Kano M, Ito M (1999) Corticotropinreleasing factor plays a permissive role in cerebellar long-term depression. Neuron 22:763-775.

Murphy BL, Arnsten AF, Goldman-Rakic PS, Roth RH (1996) Increased dopamine turnover in the prefrontal cortex impairs spatial working memory performance in rats and monkeys. Proc Natl Acad Sci USA 93:1325-1329.

Nutt DJ, Glue P, Lawson C (1990) The neurochemistry of anxiety: an update. Prog Neuropsychopharmacol Biol Psychiatry 14:737-752.

Owens MJ, Nemeroff CB (1991) Physiology and pharmacology of corticotropin-releasing factor. Pharmacol Rev 43:425-473.

Petty F, Davis LL, Kabel D, Kramer GL (1996) Serotonin dysfunction disorders: a behavioral neurochemistry perspective. J Clin Psychiatry 57 [Suppl 8]:11-16. 
Price ML, Lucki I (2001) Regulation of serotonin release in the lateral septum and striatum by corticotropin-releasing factor. J Neurosci 21:2833-2841.

Price ML, Kirby LG, Valentino RJ, Lucki I (2002) Evidence for corticotropin-releasing factor regulation of serotonin in the lateral septum during acute swim stress: adaptation produced by repeated swimming. Psychopharmacology (Berl) 162:406-414.

Radulovic J, Ruhmann A, Liepold T, Spiess J (1999) Modulation of learning and anxiety by corticotropin-releasing factor (CRF) and stress: differential roles of CRF receptors 1 and 2. J Neurosci 19:5016-5025.

Raymond JR (1991) Protein kinase C induces phosphorylation and desensitization of the human 5-HT1A receptor. J Biol Chem 266:14747-14753.

Roche M, Commons KG, Peoples A, Valentino RJ (2003) Circuitry underlying regulation of the serotonergic system by swim stress. J Neurosci 23:970-977.

Saal D, Dong Y, Bonci A, Malenka RC (2003) Drugs of abuse and stress trigger a common synaptic adaptation in dopamine neurons. Neuron 37:577-582

Sarnyai Z, Biro E, Gardi J, Vecsernyes M, Julesz J, Telegdy G (1995) Brain corticotropin-releasing factor mediates 'anxiety-like' behavior induced by cocaine withdrawal in rats. Brain Res 675:89-97.

Saudou F, Amara DA, Dierich A, LeMeur M, Ramboz S, Segu L, Buhot MC, Hen R (1994) Enhanced aggressive behavior in mice lacking 5-HT1B receptor. Science 265:1875-1878.

Sawchenko PE, Swanson LW (1989) Organization of CRF immunoreactive cells and fibers in the rat brain: immunohistochemical studies. In: Corticotropin-releasing factor: basic and clinical studies of a neuropeptide (De Souza EB, Nemeroff CB, eds), pp 29-51. Boca Raton, FL: CRC.

Shakesby AC, Anwyl R, Rowan MJ (2002) Overcoming the effects of stress on synaptic plasticity in the intact hippocampus: rapid actions of serotonergic and antidepressant agents. J Neurosci 22:3638-3644.

Shors TJ, Seib TB, Levine S, Thompson RF (1989) Inescapable versus escapable shock modulates long-term potentiation in the rat hippocampus. Science 244:224-226.

Smith GW, Aubry JM, Dellu F, Contarino A, Bilezikjian LM, Gold LH, Chen R, Marchuk Y, Hauser C, Bentley CA, Sawchenko PE, Koob GF, Vale W,
Lee KF (1998) Corticotropin releasing factor receptor 1-deficient mice display decreased anxiety, impaired stress response, and aberrant neuroendocrine development. Neuron 20:1093-1102.

Stockmeier CA (1997) Neurobiology of serotonin in depression and suicide. Ann NY Acad Sci 836:220-232.

Taylor DP (1990) Serotonin agents in anxiety. Ann NY Acad Sci 600:545-556.

Tsigos C, Chrousos GP (2002) Hypothalamic-pituitary-adrenal axis, neuroendocrine factors and stress. J Psychosom Res 53:865-871.

Turnbull AV, Rivier C (1997) Corticotropin-releasing factor (CRF) and endocrine responses to stress: CRF receptors, binding protein, and related peptides. Proc Soc Exp Biol Med 215:1-10.

Ungless MA, Singh V, Crowder TL, Yaka R, Ron D, Bonci A (2003) Corticotropin-releasing factor requires CRF binding protein to potentiate NMDA receptors via CRF receptor 2 in dopamine neurons. Neuron 39:401-407.

Xu L, Anwyl R, Rowan MJ (1997) Behavioural stress facilitates the induction of long-term depression in the hippocampus. Nature 387:497-500.

Yan Z (2002) Regulation of GABAergic inhibition by serotonin signaling in prefrontal cortex: molecular mechanisms and functional implications. Mol Neurobiol 26:203-216.

Yoshioka M, Matsumoto M, Togashi H, Saito H (1995) Effects of conditioned fear stress on 5-HT release in the rat prefrontal cortex. Pharmacol Biochem Behav 51:515-519.

Zahrt J, Taylor JR, Mathew RG, Arnsten AF (1997) Supranormal stimulation of $\mathrm{D}_{1}$ dopamine receptors in the rodent prefrontal cortex impairs spatial working memory performance. J Neurosci 17:8528-8535.

Zhong P, Gu Z, Wang X, Jiang H, Feng J, Yan Z (2003) Impaired modulation of GABAergic transmission by muscarinic receptors in a mouse transgenic model of Alzheimer's disease. J Biol Chem 278:26888-26896.

Zhou FM, Hablitz JJ (1999) Activation of serotonin receptors modulates synaptic transmission in rat cerebral cortex. J Neurophysiol 82:2989-2999.

Zohar J, Westenberg HG (2000) Anxiety disorders: a review of tricyclic antidepressants and selective serotonin reuptake inhibitors. Acta Psychiatr Scand [Suppl] 403:39-49. 